\title{
Predicting the Cost of Dental Care Using a Probability Model
}

Nadine Wehbe

University of South Florida

Advisors:

Arcadii Grinshpan, Mathematics and Statistics

Georges Raffoul, Tampa Palms Dentistry

Problem Suggested By: Nadine Wehbe

Follow this and additional works at: https://digitalcommons.usf.edu/ujmm

Part of the Mathematics Commons

UJMM is an open access journal, free to authors and readers, and relies on your support:

Donate Now

\section{Recommended Citation}

Wehbe, Nadine (2021) "Predicting the Cost of Dental Care Using a Probability Model," Undergraduate Journal of Mathematical Modeling: One + Two: Vol. 12: Iss. 1, Article 2.

DOI: https://doi.org/10.5038/2326-3652.12.1.4936

Available at: https://digitalcommons.usf.edu/ujmm/vol12/iss1/2 


\title{
Predicting the Cost of Dental Care Using a Probability Model
}

\begin{abstract}
This paper uses survey data to present a probability model that allows dental offices to predict patient costs. The quantitative model is useful for developing and accepting capitation rates. It accounts for whether the care is initial care or maintenance care, the type of dental care (such as operative, prosthetics, or periodontics), and different age groups, all of which affect the cost of dental treatment.
\end{abstract}

\section{Keywords}

dental care, capitation rate, quantitative probability model, expected value

Creative Commons License

(c) (i) (2)

This work is licensed under a Creative Commons Attribution-Noncommercial-Share Alike 3.0 United States License. 


\section{PROBLEM STATEMENT}

Predict dental treatment costs using a quantitative probability model.

\section{MOTIVATION}

While dental costs continuously fluctuate, predicting them remains universally important when managing a dental practice. The condition of uncertainty in dental treatment often poses a problem when predicting dental costs; for this reason, having a strong quantitative model is important. It allows office managers to mitigate the unknown and accurately plan and budget. Calculating the probable cost of dental care ultimately allows dentists to negotiate capitation rates that are fair and profitable. Capitation rate is predetermined rate at which insurance companies reimburse health care providers for rendered services.

\section{MATHEMATICAL DESCRIPTION AND SOLUTION APPROACH}

The data and tables in this section are retrieved from a study conducted by Boffa and Pekruhn (1975). We will begin by identifying the basic formula to calculate expected value:

\section{Equation 1}

Expected value $=P^{*} \alpha$, where $\mathrm{P}$ is a probability value $(0 \leq P \leq 1)$ and $\alpha$ is the conditional or dollar value of an event.

Next, we must address different cost factors to create our probability model. The first cost factor is age, which accounts for cost differences between adults and children. According to a study by Schoen (1974), there are cost differences between children (4-17 years) and adults (18+ years); however, it is important to note that there are not significant differences when considering different age groups within the two age categories.

Another cost factor is whether the dental treatment is initial or maintenance care. Initial care tends to be more costly than maintenance care.

Considering these two factors mentioned above, we can create a model that incorporates four mutually exclusive events and accounts for the financial dichotomy between adults and children. The four mutually exclusive events are initial year adult (IA), maintenance year adult (MA), initial year child (IC), and maintenance year child (MC). We can use the following basic equation to calculate the expected value for each user of dental care: 


\section{Equation 2}

Expected value $=\left(\mathrm{P}_{\mathrm{IA}} * \alpha_{\mathrm{IA}}\right)+\left(\mathrm{P}_{\mathrm{MA}} * \alpha_{\mathrm{MA}}\right)+\left(\mathrm{P}_{\mathrm{IC}} * \alpha_{\mathrm{IC}}\right)+\left(\mathrm{P}_{\mathrm{MC}} * \alpha_{\mathrm{MC}}\right)$

Using the probability $(\mathrm{P})$ and conditional values $(\alpha)$ from Table 1 below, we can use the equation above to calculate the total expected value for each user of dental care. Note that the probability and conditional values should be empirically derived by the manager who is calculating the total expected value.

Table 1

\begin{tabular}{|l|r|r|r|r|} 
& Probability (P) & Conditional value $(\alpha)$ & Expected value \\
\hline Initial year, adult (IA) & 0.1 & $\$ 150$ & $\$ 15$ \\
\hline Maintenance year, adult (MA) & 0.4 & $\$ 50$ & $\$ 20$ \\
\hline Initial year, child (IC) & 0.1 & $\$ 75$ & $\$ 7.50$ \\
\hline Maintenance year, child (MC) & 0.4 & $\$ 35$ & $\$ 14$ \\
\hline & & & $\$ 56.50$ \\
\hline
\end{tabular}

Expected value $=(0.1 * 150)+(0.4 * 50)+(0.1 * 75)+(0.4 * 35)=56.50$. This means that the dental office is expected to spend $\$ 56.50$ on each patient.

This model can be expanded to account for the price differences between the various types of dental services that are offered within one practice. To do this, the office manager must first empirically set a relative cost value for each type of visit.

Table 2

\begin{tabular}{|l|r|r|}
\hline & \multicolumn{3}{|c|}{ Relative cost value } \\
\hline Visit type & Adults & Children \\
\hline Operative & 5.00 & 2.61 \\
\hline Prosthetics & 8.60 & - \\
\hline Periodontics & 5.00 & - \\
\hline Endodontics & 5.30 & 1.74 \\
\hline Oral surgery & 3.20 & 2.53 \\
\hline Preventive & 1.00 & 1.02 \\
\hline Orthodontics & - & 1.58 \\
\hline
\end{tabular}

See Figures 1-5 in APPENDICES. Note that in Table 2, the cost value of 1 is equivalent to $\$ 4.50$. This is done for simplification purposes.

Next, we can further expand the model to account for age. In Table 3 below, the average number of different visits is listed for each age group. 
Table 3

\begin{tabular}{|c|c|c|c|c|}
\hline \multirow[b]{2}{*}{ Visit type } & \multicolumn{3}{|c|}{ Age group (years) } & \multirow[b]{2}{*}{$55+$} \\
\hline & $4-17$ & $18-34$ & $35-54$ & \\
\hline Operative & 1.2 & 2.4 & 2.5 & 1.2 \\
\hline Prosthetics & 0.0 & 1.0 & 1.0 & 4.2 \\
\hline Periodontics & 0.0 & 0.3 & 1.5 & 0.1 \\
\hline Endodontics & 1.0 & 1.7 & 0.4 & 0.8 \\
\hline Oral surgery & 1.1 & 0.6 & 1.0 & 0.3 \\
\hline Preventive & 0.7 & 0.6 & 0.1 & - \\
\hline Orthodontics & 0.3 & 0.0 & 0.0 & 0.0 \\
\hline Conditional value & 8.8 & 34.0 & 34.0 & 47.3 \\
\hline
\end{tabular}

We can solve for the conditional values for each age group above by adding the product of the average number of visits (Table 3 ) by the relative cost value (Table 2). This is represented by Equation 3 below.

\section{Equation 3}

$\mathrm{CV}=\left(\right.$ average number of visits operative ${ }^{*}$ relative cost value operative $)+($ average number of visits prosthetics * relative cost value prosthetics $)+($ average number of visits periodontics * relative cost value periodontics $)+\ldots$ (average number of visits orthodontics * relative cost value orthodontics)

For example, the conditional value for 4-17 years is $\$ 39.60$. We can solve for this by using Equation 3.

$\mathrm{CV}=(1.2) *(2.61)+(1.0) *(1.74)+(1.1) *(2.53)+(0.7) *(1.02)+(0.3) *(1.58)=8.843$

The true cost value is $\$ 39.79(8.843 * \$ 4.50)$. The cost value of 1 is equivalent to $\$ 4.50$, as mentioned below Table 2 .

Many patients come in for an operative procedure as a subevent/initial session, for example, and then end up needing services that are considered different visit types. Conditional values can be calculated for these cases. If we look at just one category from Table 1, such as initial year, adult (IA), we can compose the chart below to account for patients who come in for multiple visit types. 
Table 4

Five subevents based on first treatment session, with their distribution of average number of visit types per adult for initial year of care and respective conditional values

\begin{tabular}{|c|c|c|c|c|c|c|c|}
\hline Initial session & operative & prosthetics & periodontics & endodontics & $s$ oral surgery & preventive & conditional values \\
\hline operative & 2.7 & 1.7 & 0.1 & 0.7 & 0.4 & 0.7 & 34.8 \\
\hline prosthetics & 0.4 & 5.0 & 0.2 & 0.4 & - & - & 48.1 \\
\hline periodontics & 2.3 & 0.5 & 4.4 & - & - & 0.8 & 38.6 \\
\hline endodontics & 2.6 & 3.4 & 0.5 & 6.4 & 0.5 & 1.0 & 80.7 \\
\hline oral surgery & 2.6 & 0.8 & 0.8 & - & 2.4 & 0.4 & 31.3 \\
\hline
\end{tabular}

The conditional values in Table 4 are calculated by using Equation 3. The relative cost value corresponding to each subevent is taken from Table 2. For example, this is how the conditional value of operative initial session is found:

$\mathrm{CV}=(2.7 * 5.00)+(1.7 * 8.60)+(0.1 * 5.00)+(0.7 * 5.30)+(0.4 * 3.20)+(0.7 * 1.00)=34.31$

The true cost value is $\$ 154.4(34.31 * 4.50)$.

Finally, to calculate the expected value based on the conditional values, two factors are necessary: $\mathrm{P}_{\mathrm{i}}$ (the proportion of sample patients in percentages) and $C \mathrm{~V}_{\mathrm{i}}$ (conditional values). $\mathrm{P}_{\mathrm{i}}$ values can be determined empirically and $\mathrm{CV}_{\mathrm{i}}$ values can be taken from Table 4.

\section{Table 5}

\begin{tabular}{l|r|r|r}
\hline Expected value (EV) of initial year care of adults & & \\
\hline Subevents (initial sessions) & $\mathrm{Pi}$ & $\mathrm{CV}$ & 34.8 \\
\hline Operative (1) & 45 & 48.1 \\
\hline Prosthetics (2) & 5 & 38.6 \\
\hline Periodontics (3) & 20 & 80.7 \\
\hline Endodontics (4) & 10 & 31.3 \\
\hline Oral surgery (5) & 20 & & \\
\hline
\end{tabular}

Table 5 above is based on the final equation that is used to determine expected value, in this case, of initial year care of adults. The equation used is shown below

\section{Equation 4}

$\mathrm{EV}_{\mathrm{IA}}=\left(\mathrm{P}_{1} * \mathrm{CV}_{1}\right)+\left(\mathrm{P}_{2} * \mathrm{CV}_{2}\right)+\left(\mathrm{P}_{3} * \mathrm{CV}_{3}\right)+\left(\mathrm{P}_{4} * \mathrm{CV}_{4}\right)+\left(\mathrm{P}_{5} * \mathrm{CV}_{5}\right)=40.12$

The true cost value is $\$ 180.54(40.12 * 4.50)$. 


\section{DISCUSSION}

While the cost of dental care has undoubtedly increased since this model is proposed, this model remains useful for dentists or dental managers who are working with insurance companies. For example, in a private dental practice which provides the subevents listed above (Table 5), the estimated value of initial year care of adult is $\$ 180.54$. Based on this information, a dentist can determine whether the capitation rates that are being provided by insurance companies are profitable enough for the dental office.

\section{CONCLUSIONS AND RECOMMENDATIONS}

Withal, this probability model is useful because it allows dental practices to predict dental costs. By taking into account different types of dental care, age groups, and whether the care is initial or maintenance, dental practices can better understand capitation rates. It is important to note that this model is developed based on data from a general practice, and for this reason, is recommended to be used by general dentists. Refinements would be necessary in order to allow this model to work for specialized dental practices.

\section{NOTATIONS}

$\mathrm{P}$ is a probability value $(0 \leq P \leq 1)$.

Expected value: $P^{*} \alpha$, where $\alpha$ is the conditional or dollar value of an event.

Initial year adult: IA

$\mathrm{EV}_{\mathrm{IA}}$ : Expected value of initial year care of adults

Maintenance year adult: MA

Initial year child: IC

Maintenance year child: MC

CV: Conditional value

$\mathrm{P}_{\mathrm{i}}$ : the proportion of sample patients in percentages 


\section{APPENDICES}

\section{Figure 1: Operative (dental bonding)}

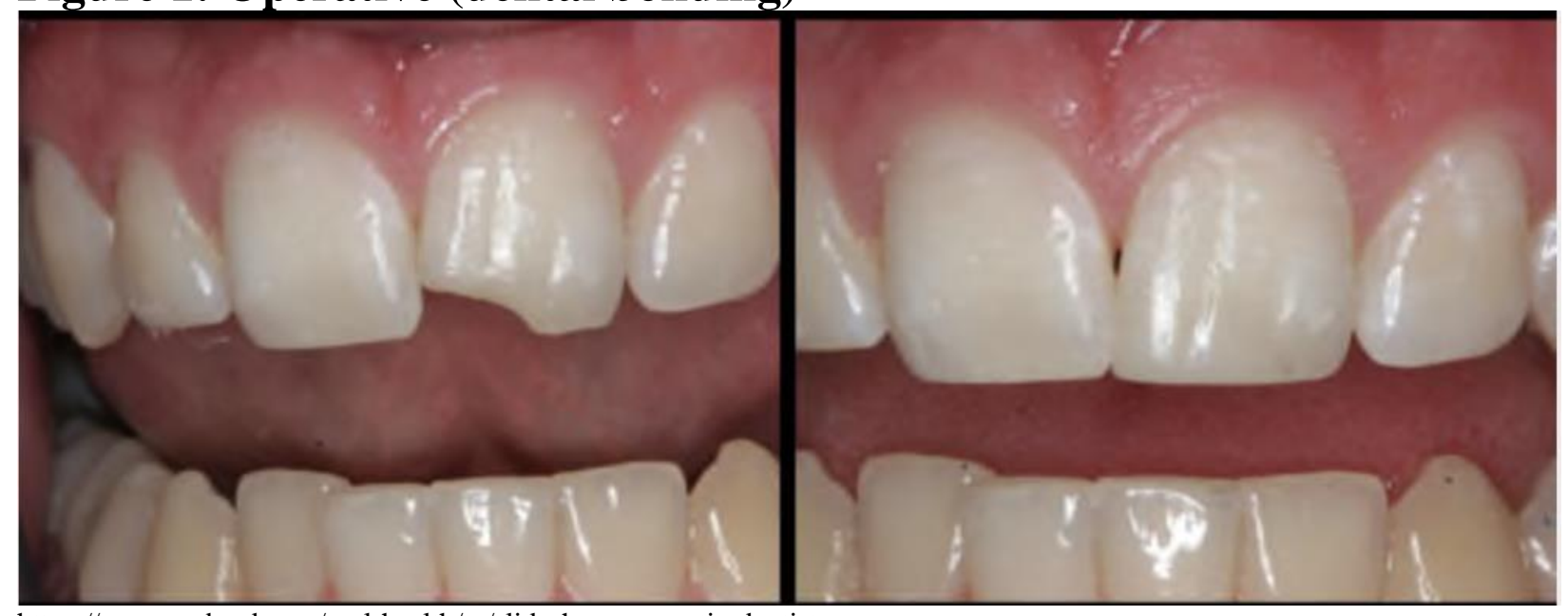

https://www.webmd.com/oral-health/ss/slideshow-cosmetic-dentistry

\section{Figure 2: Prosthetics (implants)}

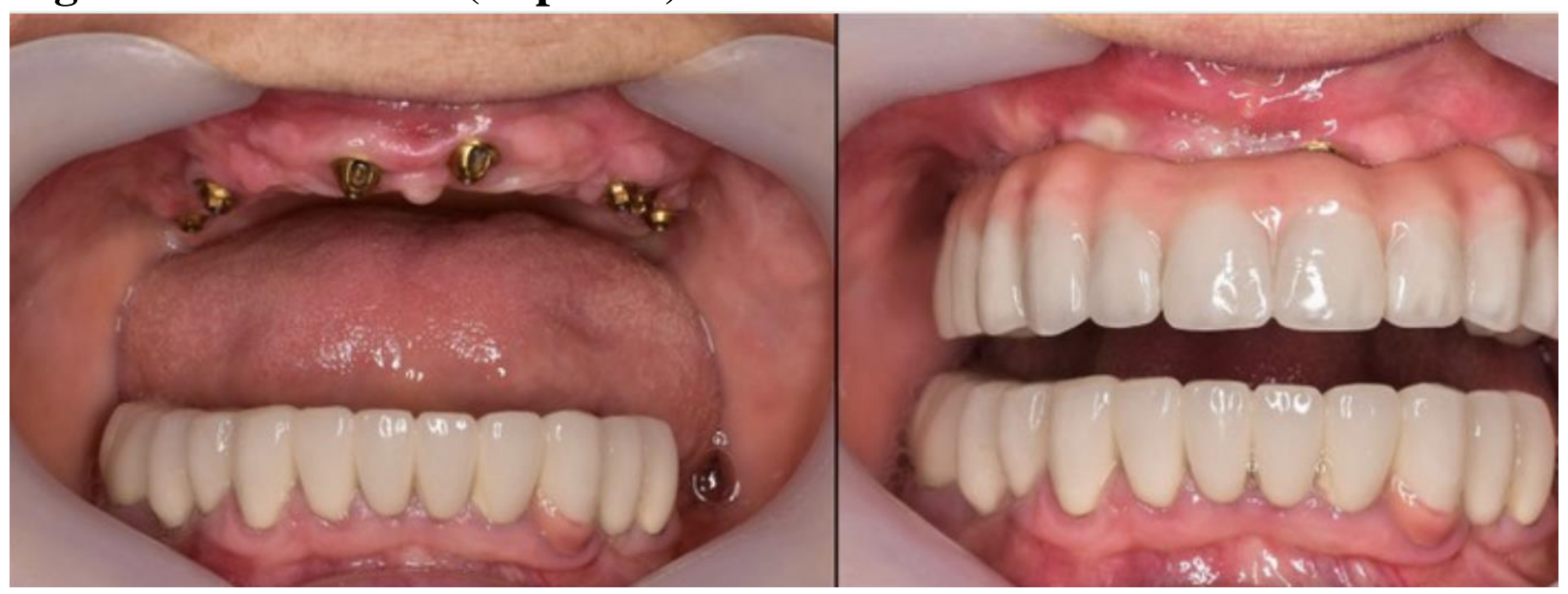

https://www.shutterstock.com/search/dental+prosthesis

\section{Figure 3: Periodontics (scaling and root planning)}




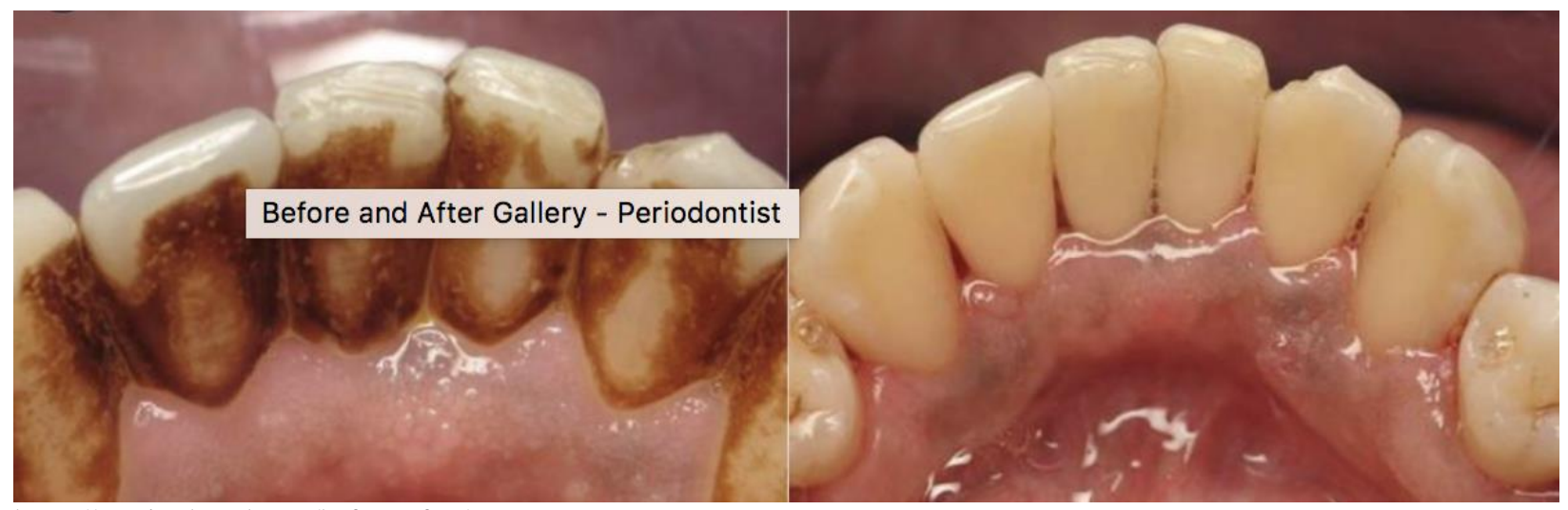

https://sonrisadental.com/before-after/

Figure 4: Endodontics (root canal)

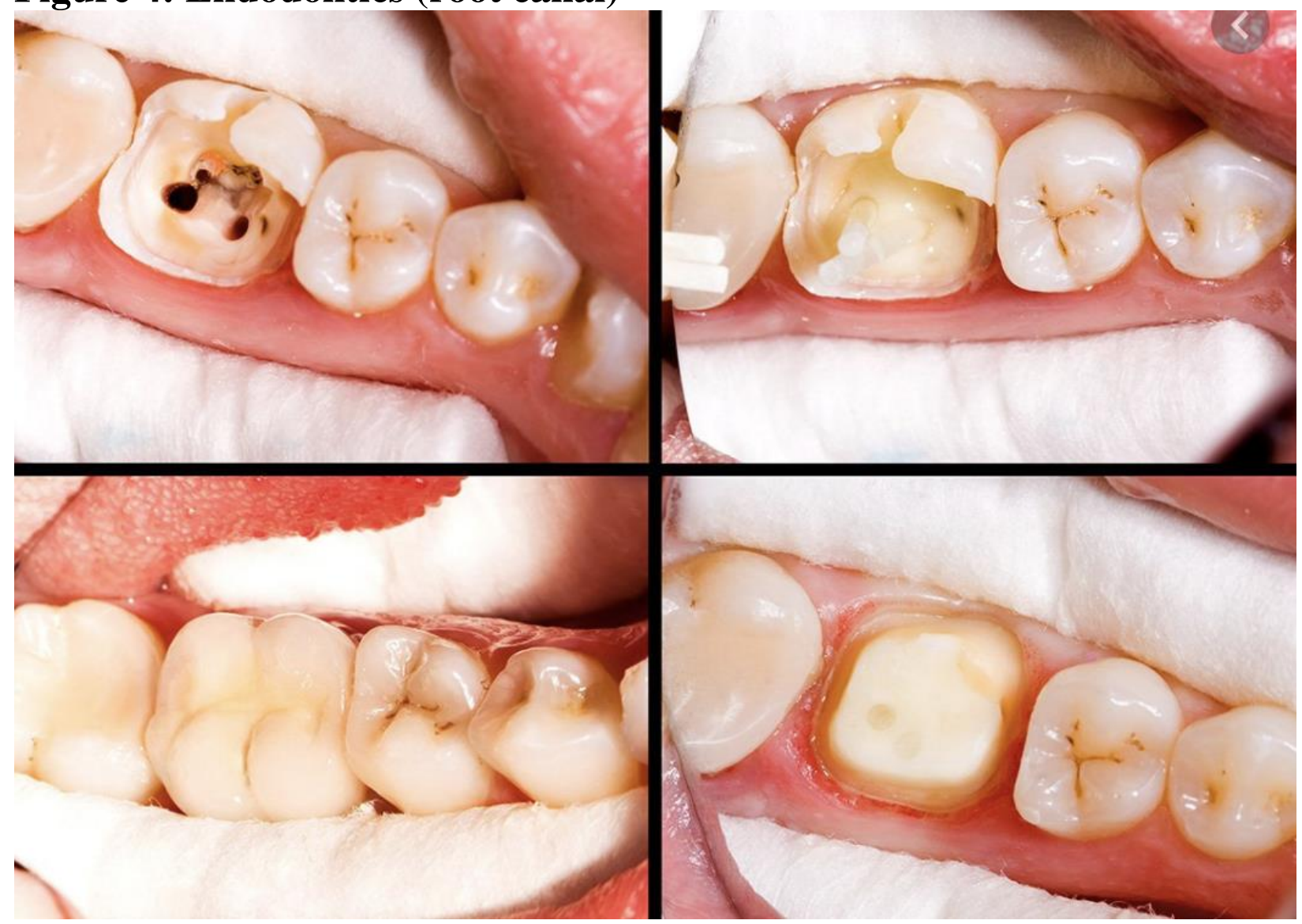

https://askthedentist.com/root-canals-know-before-you-go/

Figure 5: Oral surgery (wisdom tooth removal) 


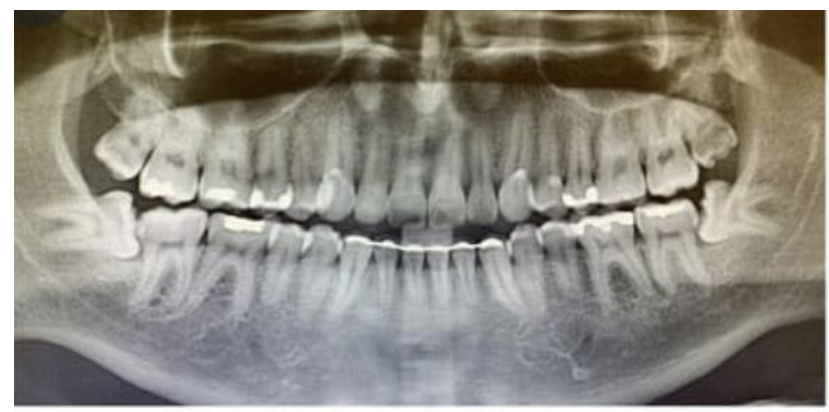

Before

https://www.waydental.com/wisdom-tooth-extraction.html

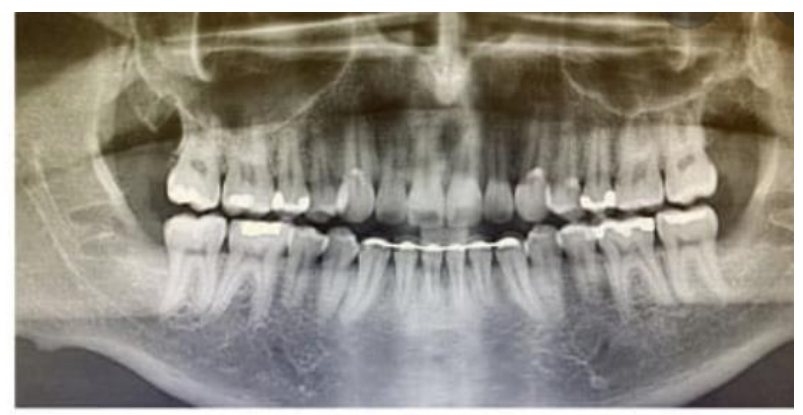

After

\section{REFERENCES}

Joseph Boffa and Richard Pekruhn (1975). Prediction of dental care costs by use of a probability model. Public Health Reports, 90(6), 528-531.

M. H. Schoen (1974). Methodology of capitation payment to group dental practice and effects of such payment on care. Health services reports, 89(1), 16-24. 